Pacific Journal of Mathematics

CONTINUITÉ DU SPECTRE DANS LES ALGÈbRES DE 


\section{CONTINUITÉ DU SPECTRE DANS LES ALGÈBRES DE BANACH AVEC INVOLUTION.}

\section{BERnARd AUpetit}

Let $A$ a complex Banach algebra with an involution. If the spectral radius is submultiplicative on the set of hermitian elements the spectrum is continuous on the set of normal elements. From this we conclude that the set of hermitian elements with real spectrum is closed in the set of hermitian elements, which generalizes a result of $B$. Yood.

Soit $A$ une algèbre de Banach complexe munie d'une involution $x \rightarrow x^{*}$. On dénote par $H$ et $N$ les ensembles des éléments hermitiens (c'est-à-dire vérifiant $x=x^{*}$ ) et des éléments normaux (c'est-à-dire vèrifiant $\left.x x^{*}=x^{*} x\right)$, par $\rho$ le rayon spectral. Plus loin nous désignerons par $\tilde{A}$ l'algèbre obtenue de $A$ par adjonction d'une unité si $A$ n'a pas d'unité, avec la norme $\|x+\lambda 1\|=\|x\|+|\lambda|$ et l'involution $(x+\lambda 1)^{*}=x^{*}+\bar{\lambda} 1$ et $\tilde{A}=A$ si $A$ a une unité.

DÉFInItIon 1. On dit que $\rho$ est sous-multiplicatif sur $H$ s'il existe $\alpha>0$ tel que $\rho(a b) \leqq \alpha \rho(a) \rho(b)$ quels que soient $a$ et $b$ dans $H$.

Etant donnés deux ensembles compacts $K_{1}$ et $K_{2}$ de $\mathbf{C}$, la distance de Hausdorff $\delta\left(K_{1}, K_{2}\right)$ est définie par:

$\delta\left(K_{1}, K_{2}\right)=\operatorname{Max}\left(\operatorname{Sup}_{x \in K_{2}} d\left(x, K_{1}\right), \operatorname{Sup}_{x \in K_{1}} d\left(x, K_{2}\right)\right)$ où $d(x, K)$

$$
=\operatorname{Inf}_{y \in K}|x-y| .
$$

Définition 2. La fonction $x \mapsto S p x$ est dite continue si elle est continue pour la distance de Hausdorff.

Pour tous les détailsconcernant cette définition voir Newburgh [2].

THÉORÈme. Si $\rho$ est sous-multiplicatif sur l'ensemble des éléments hermitiens alors $x \mapsto S p x$ est continue sur l'ensemble des éléments normaux.

Démonstration. A la rigueur en raisonnant dans $A / \operatorname{Rad} A$, ce qui ne change pas le spectre puisque $S p \dot{x}=S p x$ en appelant $\dot{x}$ la classe de $x$, on peut supposer que l'involution est continue (ces résultats bien connus sont tous deux cités dans [5]). Supposons le spectre non continu sur $N$, alors il existe $x$ normal et $x_{n}$ normaux qui tendent vers $x$, quand $n$ tend vers l'infini, ainsi que $\epsilon>0$ et $\lambda_{0} \in S p x$ tels que: 


\section{$\left|\lambda_{0}-\lambda\right|>\epsilon$ pour tout $\lambda \in S p x_{n}$, quel que soit $n$ entier.}

Premier cas. Si $\lambda_{0}=0$, alors comme $\lambda_{0} \notin S p x_{n}, x_{n}$ est inversible donc $A$ admet une unité et $\rho\left(x_{n}^{-1}\right)=\rho\left(x_{n}^{*-1}\right)<1 / \epsilon$ puisque:

$$
S p x_{n}^{\prime \prime}=\left\{\frac{1}{\lambda} \mid \lambda \in S p x_{n}\right\}
$$

Alors $u_{n}=x_{n} x_{n}^{*}$ est inversible et tend vers $u=x x^{*}$. On $a: 1-u_{n}^{-1}=$ $\left(u_{n}-u\right) u_{n}^{-i}$ et $u_{n}^{-1}$ hermitien donc,

$$
\rho\left(1-u u_{n}^{-1}\right) \leqq \alpha \rho\left(u_{n}^{-1}\right) \rho\left(u_{n}-u\right) \leqq \frac{\alpha}{\epsilon}\left\|u_{n}-u\right\|
$$

qui tend vers 0 quand $n$ tend vers l'infini donc d'après le lemme 1.4 .18 de [3], $u$ est inversible à droite. En raisonnant avec $u_{n}^{-1} u$ on obtient que $u$ est inversible, donc $x$ inversible, ce qui est absurde.

Deuxième cas. Supposons $\lambda_{0} \neq 0$ et plaçons nous dans $\tilde{A}$, alors $1-\left(x_{n} / \lambda_{0}\right)$ tend vers $1-\left(x / \lambda_{0}\right)$. Comme l'involution est supposée continue dans $A$ elle est continue dans $\tilde{A}$, donc $1-\left(x_{n}^{*} / \bar{\lambda}_{0}\right)$ tend vers $1-\left(x^{*} / \overline{\lambda_{0}}\right)$. Si $\lambda \in S p\left(x_{0} / \lambda_{0}\right)$ alors $\lambda \lambda_{0} \in S p x_{n}$ donc $\left|\lambda \lambda_{0}-\lambda_{0}\right|>\epsilon$ ainsi:

$$
S p\left(1-\frac{x_{n}}{\lambda_{0}}\right)^{-1}=\left\{\frac{1}{1-\lambda} \mid \lambda \in \operatorname{Sp} \frac{x_{n}}{\lambda_{0}}\right\}=\left\{\frac{\lambda_{0}}{\lambda_{0}-\lambda \lambda_{0}} \mid \lambda \in S p \frac{x_{n}}{\lambda_{0}}\right\}
$$

d'où:

$$
\rho\left(\left(1-\frac{x_{n}}{\lambda_{0}}\right)^{-1}\right) \leqq \frac{\left|\lambda_{0}\right|}{\epsilon}
$$

Par un raisonnement identique:

$$
\rho\left(\left(1-\frac{x_{n}^{*}}{\lambda_{0}}\right)^{-1}\right) \leqq \frac{\left|\lambda_{0}\right|}{\epsilon} .
$$

Posons $u_{n}=\left(1-\frac{x_{n}}{\lambda_{0}}\right)\left(1-\frac{x_{n}^{*}}{\bar{\lambda}_{0}}\right)$ et $u=\left(1-\frac{x}{\lambda_{0}}\right)\left(1-\frac{x^{*}}{\lambda_{0}}\right)$. Comme $x_{n}$ et $x_{n}^{*}$ commutent on obtient:

$$
\rho\left(u_{n}^{-1}\right) \leqq \frac{\left|\lambda_{0}\right|^{2}}{\epsilon^{2}}
$$

Posons $u_{n}=1+h_{n}$ où $h_{n}$ est hermitien dans $A$. L'inverse de $u_{n}$ est hermitien dans $A$ donc de la forme $v_{n}+\mu_{n}$. Mais de: 


$$
\left(1+h_{n}\right)\left(\mu_{n} 1+v_{n}\right)=\left(\mu_{n} 1+v_{n}\right)\left(1+h_{n}\right)=1
$$

on obtient que $\mu_{n}=1$.

Pour $n$ assez grand de façon que $\left\|u-u_{n}\right\|<1$ alors:

$$
\begin{aligned}
u & =u_{n}+u-u_{n}=u_{n}\left[1+u_{n}^{-1}\left(u-u_{n}\right)\right]=u_{n}\left[1+\left(1+v_{n}\right)\left(u-u_{n}\right)\right] \\
& =u_{n}\left[1+u-u_{n}+v_{n}\left(u-u_{n}\right)\right] \\
& =u_{n}\left[1+v_{n}\left(u-u_{n}\right)\left(1+u-u_{n}\right)^{-1}\right] \cdot\left(1+u-u_{n}\right)
\end{aligned}
$$

or $\left(u-u_{n}\right)\left(1+u-u_{n}\right)^{-1}=\sum_{k=0}^{\infty}(-1)^{k}\left(u-u_{n}\right)^{k+1}$ est dans $H$, qui est fermé puisque l'involution est continue. Comme $\rho$ est sous-multiplicatif, sur $H$ on obtient:

$$
\rho\left(v_{n}\left(u-u_{n}\right)\left(1+u-u_{n}\right)^{-1}\right) \leqq \alpha \rho\left(v_{n}\right) \rho\left(\left(u-u_{n}\right)\left(1+u-u_{n}\right)^{-1}\right) .
$$

Mais $v_{n}=u_{n}^{-1}-1$ donc d'après (1), $\rho\left(v_{n}\right) \leqq 1+\left(\left|\lambda_{0}\right|^{2} / \epsilon^{2}\right)$ de plus $\rho\left(\left(u-u_{n}\right)\left(1+u-u_{n}\right)^{-1}\right)$ tend vers zéro quand $u_{n}$ tend vers $u$, donc d'après (2), (3) et le Lemme 1.4.18 de [3], $u$ est inversible, d'où $1-\left(x / \lambda_{0}\right)$ est inversible, ce qui est contradictoire.

Remarque 1. Sans modifier la démonstration on voit que le spectre est continu sur l'ensemble des $x$ tels que $\rho\left(x x^{*}\right) \leqq \rho(x)^{2}$.

Remarque 2. En reprenant la démonstration, il est possible de prouver que si $\rho$ est sous-multiplicatif sur une algèbre $A$, pas nécessairement involutive, alors $\rho$ est continu sur tout $A$. En fait, dans ce cas $A / \operatorname{Rad} A$ est commutative (voir [1]).

Voici quelques corollaires qui découlent immédiatement du théorème.

Corollaire 1. Si $\rho$ est sous-multiplicatif sur $H$ et si $\beta>0$, l'ensemble des éléments normaux dont le rayon spectral est inférieur ou égal à $\beta$ est fermé dans $N$.

Corollaire 2. Si $\rho$ est sous-multiplicatif sur $H$, l'ensemble des éléments hermitiens dont le spectre est réel est fermé dans $H$.

Corollaire 3. (B. Yood [6]) S'il existe $\gamma>0$ tel que $\rho(x) \geqq \gamma\|x\|$ quel que soit $x \in H$ alors l'ensemble des éléments hermitiens dont le spectre est réel est fermé dans $A$. 
Démonstration. D'après [4], l'involution est continue, donc $H$ est fermé dans $A$. De plus si $a, b \in H$ on $a$ :

$$
\rho(a b) \leqq\|a b\| \leqq\|a\| \cdot\|b\| \leqq \frac{1}{\gamma^{2}} \rho(a) \rho(b)
$$

et on applique le corollaire précédent.

Remarque 3. On peut aussi démontrer le résultat de B. Yood à l'aide des résultats de Newburgh [2], cités dans [3] p. 37.

Corollaire 4. Si A est une algèbre symétrique alors le spectre est continu sur l'ensemble des éléments normaux.

Démonstration. Cela résulte du fait que $\rho$ est sous-multiplicatif sur $H$. En utilisant la sous-additivité de $\rho$ sur $N$ on peut aussi montrer que l'enveloppe convexe du spectre est uniformément continue sur $N$.

QuEstions. Est-il vrai que si $\rho$ est sous-multiplicatif sur $H$ alors le spectre est uniformément continu sur $N$ (toujours au sens de la distance $\delta)$ ? Quelles sont les algèbres involutives telles que $\rho$ soit sousmultiplicatif sur $H$ ?

* Pendant le délai de révision de ce travail l'auteur n'a résolu complètement aucun de ces deux problèmes. Cependant pour la première question il a pu prouver que l'enveloppe convexe du spectre est uniformément continue sur $H$ parce que $\rho$ est sous-additif sur $H$.

\section{RÉFÉRENCES}

1. B. Aupetit, Caractérisation spectrale des algèbres de Banach commutatives, à paraître.

2. J. D. Newburgh, The variation of spectra, Duke Math. J., 18 (1951), 165-176.

3. C. E. Rickart, General Theory of Banach algebras, D. Van Nostrand Co, Princeton, 1960.

4. B. Yood, Topological properties of homomorphisms between Banach algebras, Amer. J. Math., 76 (1954), 155-167.

5. _- Continuity for linear maps on Banach algebras, Studia Math., 31 (1968), 263-266.

6. - On axioms for $B^{*}$-algebras, Bull. Amer. Math. Soc., 76 (1970), 80-82.

Received November 26, 1973, and in revised form May 21, 1974. 


\section{PACIFIC JOURNAL OF MATHEMATICS \\ EDITORS}

\author{
Richard ARENS (Managing Editor) \\ University of California \\ Los Angeles, California 90024
}

\author{
R. A. Beaumont \\ University of Washington \\ Seattle, Washington 98105
}

\section{J. DugundJI}

Department of Mathematics

University of Southern California

Los Angeles, California 90007

D. Gilbarg and J. Milgram

Stanford University

Stanford, California 94305

\section{ASSOCIATE EDITORS}
E. F. BECKENBACH
B. H. NeumanN
F. WOLF
K. YoshidA

\section{SUPPORTING INSTITUTIONS}

\author{
UNIVERSITY OF BRITISH COLUMBIA \\ CALIFORNIA INSTITUTE OF TECHNOLOGY \\ UNIVERSITY OF CALIFORNIA \\ MONTANA STATE UNIVERSITY \\ UNIVERSITY OF NEVADA \\ NEW MEXICO STATE UNIVERSITY \\ OREGON STATE UNIVERSITY \\ UNIVERSITY OF OREGON \\ OSAKA UNIVERSITY
}

\author{
UNIVERSITY OF SOUTHERN CALIFORNIA \\ STANFORD UNIVERSITY \\ UNIVERSITY OF TOKYO \\ UNIVERSITY OF UTAH \\ WASHINGTON STATE UNIVERSITY \\ UNIVERSITY OF WASHINGTON \\ AMERICAN MATHEMATICAL SOCIETY
}

The Supporting Institutions listed above contribute to the cost of publication of this Journal, but they are not owners or publishers and have no responsibility for its contents or policies.

Mathematical papers intended for publication in the Pacific Journal of Mathematics should be in typed form or offset-reproduced (not dittoed), double spaced with large margins. Underline Greek letters in red, German in green, and script in blue. The first paragraph or two must be capable of being used separately as a synopsis of the entire paper. Items of the bibliography should not be cited there unless absolutely necessary, in which case they must be identified by author and Journal, rather than by item number. Manuscripts, in duplicate, may be sent to any one of the four editors. Please classify according to the scheme of Math. Reviews, Index to Vol. 39. All other communications should be addressed to the managing editor, or Elaine Barth, University of California, Los Angeles, California, 90024.

100 reprints are provided free for each article, only if page charges have been substantially paid. Additional copies may be obtained at cost in multiples of 50 .

The Pacific Journal of Mathematics is issued monthly as of January 1966. Regular subscription rate: $\$ 72.00$ a year (6 Vols., 12 issues). Special rate: $\$ 36.00$ a year to individual members of supporting institutions.

Subscriptions, orders for back numbers, and changes of address should be sent to Pacific Journal of Mathematics, 103 Highland Boulevard, Berkeley, California, 94708.

PUBLISHED BY PACIFIC JOURNAL OF MATHEMATICS, A NON-PROFIT CORPORATION Printed at Jerusalem Academic Press, POB 2390, Jerusalem, Israel.

$$
\begin{gathered}
\text { Copyright (c) } 1975 \text { Pacific Journal of Mathematics } \\
\text { All Rights Reserved }
\end{gathered}
$$




\section{Pacific Journal of Mathematics}

Vol. 56, No. 2 December, 1975

Ralph Alexander, Generalized sums of distances .................. 297

Zvi Arad and George Isaac Glauberman, A characteristic subgroup of a group of odd order ............................... 305

B. Aupetit, Continuité du spectre dans les algèbres de Banach avec involution ........................................ 321

Roger W. Barnard and John Lawson Lewis, Coefficient bounds for some classes of starlike functions . ...........................

Roger W. Barnard and John Lawson Lewis, Subordination theorems for some classes of starlike fumctions . .................... 333

Ladislav Bican, Preradicals and injectivity .................. 367

James Donnell Buckholtz and Ken Shaw, Series expansions of analytic

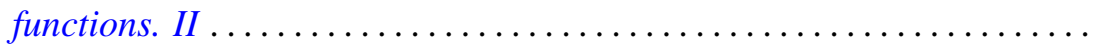

Richard D. Carmichael and E. O. Milton, Distributional boundary values in

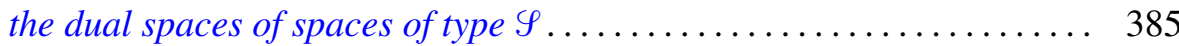

Edwin Duda, Weak-unicoherence ............................ 423

Albert Edrei, The Padé table of functions having a finite number of essential singularities ........................................

Joel N. Franklin and Solomon Wolf Golomb, A function-theoretic approach to the study of nonlinear recurring sequences ................ 455

George Isaac Glauberman, On Burnside's other $p^{a} q^{b}$ theorem 469

Arthur D. Grainger, Invariant subspaces of compact operators on topological vector spaces .........................

Jon Craig Helton, Mutual existence of sum and product integrals .

Franklin Takashi Iha, On boundary functionals and operators with finite-dimensional null spaces

Gerald J. Janusz, Generators for the Schur group of local and global number fields

A. Katsaras and Dar-Biau Liu, Integral representations of weakly compact operators.

W. J. Kim, On the first and the second conjugate points .

Charles Philip Lanski, Regularity and quotients in rings with involution ....

Ewing L. Lusk, An obstruction to extending isotopies of piecewise linear manifolds.

Saburou Saitoh, On some completenesses of the Bergman kernel and the Rudin kernel..

Stephen Jeffrey Willson, The converse to the Smith theorem for $Z_{p}$-homology spheres. 